\title{
Nature of "STEM"?
}

\section{Epistemic Underpinnings of Integrated Science, Technology, Engineering, and Mathematics in Education}

\section{Sibel Erduran ${ }^{1}$}

Published online: 24 July 2020

(C) Springer Nature B.V. 2020

In recent years, there has been an increasing emphasis on STEM (science, technology, engineering, and mathematics) education in international curriculum and policy documents (e.g., NSTA, 2020; Office of the Chief Scientist, 2014). A key argument in the proposals for STEM education is that science, technology, engineering, and mathematics workers play a pivotal role in economic growth and STEM education produces critical thinkers, scientifically literate professionals and citizens, and enables the next generation of innovators. The infusion of "engineering practices" in the Next Generation Science Standards in the USA signals a major shift in curriculum policy for integrating related domains to science teaching and learning. Furthermore, there has been plethora of journals, research centers, and community organizations that have made STEM a central educational goal, and many funding agencies are supporting research and development efforts to advance STEM education.

But what exactly does "STEM" mean? Is there a particular "nature" to STEM or are there disciplinary variations across the "natures" of science, technology, engineering, and mathematics? What are the epistemic underpinnings of STEM and what do they imply for STEM education? A question in a similar vein had been raised by Erin Peters-Burton in an editorial of School Science and Mathematics a few years ago (Peters-Burton, 2014) but has since received little attention despite the wealth of interest in research on STEM education. The primary purpose of this special issue is, then, to address some questions about the nature of STEM and STEM education. The questions raised by the papers in the special issue relate to theoretical characterization of STEM as well as a range of educational considerations including the implications for curriculum reform as well as for students' and teachers' learning.

A fundamental issue is whether or not "STEM" is a warranted notion in the first place. Despite the plethora of work on STEM education, what STEM promises to be and how it manifests itself in education can be questioned. Hence, the special issue is set against a backdrop of some critiques of STEM education, followed by a set of studies that illustrate its merits. Reynante, Selback-Allen, and Pimentel question how many STEM education efforts have not explicitly accounted for the distinct epistemologies of the disciplines. The authors critically examine the concept of integrated

Sibel Erduran

Sibel.Erduran@education.ox.ac.uk

1 Department of Education, University of Oxford, 15 Norham Gardens, Oxford OX2 6PY, UK 
STEM by conducting a thematic analysis of K-12 STEM learning standards documents to identify cross-cutting themes among the practices of the various disciplines. They identify eight crosscutting themes: communicating, investigating, modeling, using tools, working with data, making sense of problems or phenomena, solving problems, and evaluating ideas or solutions. Hence, they present not only the opportunities but also the potential perils, which consist of conflation and/or exclusion of various STEM practices and epistemologies. McComas and Burgin, on the other hand, caution that STEM education is being promoted on the tenuous empirical and philosophical foundation and thus educators should be reflecting on the context of how and why STEM is relevant in schooling.

Following the critical stance of the first two papers, a set of papers investigate what is meant by "STEM" more closely. Pleasants argues for the need to clarify the nature of STEM problems and differentiate STEM problems from those of different kinds. A typology is introduced that situates STEM problems within a broader space of problems within STEM and non-STEM fields, and the characteristics of STEM problems are described. The typology and characteristics are then applied to different approaches to STEM instruction. A key conclusion is that many integrated STEM education efforts tend to focus on STEM problems that are narrowly framed and they do not include attention to social, cultural, political, or ethical dimensions. Ortiz-Revilla, Aduriz-Bravo, and Greca further question the philosophical undertones of STEM and highlight humanist values for integrated STEM education. Following a set of proposed relationships between the STEM knowledge areas, they adopt a model of a "seamless web" for such relationships that is coherent with humanist values. A few issues emerging from this model are addressed through the lens of the so-called family resemblance approach, a framework from the field of research on the nature of science, in order to identify some potential central features of "nature of STEM". Quinn, Reid, and Gardner propose a model of "nature of STEM" (NOSTEM) in light of the siloed individual disciplines by considering the dimensions of each. They argue that NOSTEM is congruent with the nature of engineering (NOE). Having highlighted the congruence between their accounts of NOSTEM and NOE, the authors charge scholars to investigate critical aspects of the nature of engineering knowledge.

The next three papers focus on how STEM is situated in science curricula and what specific foci are relevant for design of curricula. Park, $\mathrm{Wu}$, and Erduran report on an analysis of science education reform documents from the USA, Korea, and Taiwan. They compare the representation of the nature of STEM disciplines in science curriculum standards using the framework of the family resemblance approach, presenting a comparative analysis based on disciplinary aims, values, and practices. The results illustrate that the features specific to science and shared by science and engineering were most frequently addressed in the standards documents, whereas mathematics-related features were rarely mentioned. Furthermore, they observe variation in the coverage in terms of the nature of STEM disciplines. Next, Millar investigates the influences that have resulted in the current interpretation of STEM as well as the epistemological questions, tensions, and issues that such interpretation raises. The author considers previous and current curriculum reform efforts and debates, and she raises questions about the underlying assumptions. On the other hand, Develaki brings a particular focus to curriculum content by providing a comparative analysis of modeling and argumentation as cross-cutting themes in mathematics, science, and engineering, and notes the observed similarities, intersections, and differences in these fields. A key contribution of the paper is the differentiation and clarification of what is meant by "model" and "argument" in empirical sciences versus mathematics. 
Engineering, as a relatively recent consideration in science education research, centers in the next two papers. McGowan and Bell present the position that diversifying participation in engineering means that STEM education should not only engage young people in engineering practices and structures, but also take a critical look at the field of engineering education. They investigate diverse histories, epistemologies, and ways of knowing in engineering in order to outline the possibilities for broadening participation in engineering in schools. Although there is recognition of the importance of engineering education and major curriculum standard documents such as the Next Generation Science Standards calling for the inclusion of engineering in science education, the question remains as to how familiar science teachers are with engineering and thus can engage with its teaching. The issue of teachers' learning of engineering practices is picked again in Mangiante and Gabriele-Black's paper which reports about a multiple case study examining one professional development approach to improve teachers' understanding and implementation of the STEM discipline of engineering. Two teams of elementary teachers analyzed their students' written work and assessments during facilitated professional learning community sessions with a science/engineering education researcher after their first implementation of an engineering design unit. The results indicated that the teachers noticed students' understandings and misconceptions about the work of engineers, the disciplinary language for a specific engineering unit, the operational mechanism of a design, and engineering epistemic practices. The findings from this study have implications for forms of professional development that sustain teacher learning about engineering design.

STEM education efforts have highlighted the importance of computing in relation to science education. Christensen and Lombardi present a background to how computing has emerged in STEM education literature and the challenges it poses for science education partly due to the fact that it can be a fairly elusive and broad concept. The authors argue that computational thinking can be integrated into science content such as evolution in order to overcome misconceptions and reinforce understanding of the nature of science. They present a learning progression, which outlines biological evolution learning coupled with computational thinking. The define components of computational thinking (input, integration, output, and feedback) are integrated with biology. The complex nature of both teaching computational thinking and biological evolution are illustrated in a concrete learning progression.

The timeframe for the compilation of the papers in this special issue coincided with the emergence of the COVID-19 pandemic. My April editorial of Science \& Education (Erduran, 2020) made a call for papers related to the theme of how history, philosophy, and sociology of science (HPS) can potentially contribute to the understanding of and solution to the pandemic. One outcome of this call is a position paper by Michael Reiss who highlights the importance of interdisciplinarity for science education. The author illustrates the shortcomings in the ways that HPS is often used in school science, and points to how knowledge of previous pandemics might help in teaching about COVID19. The special issue thus concludes with the message that STEM education will be well served when societal problems such as the COVID-19 pandemic are viewed through the interdisciplinary lenses of HPS. Overall, the special issue has illustrated how epistemic perspectives on STEM may help clarify what is meant by "STEM" and how educational efforts about STEM can be enhanced. 


\section{Compliance with ethical standards}

Conflict of Interest The author declares no conflict of interest.

\section{References}

Erduran, S. (2020). Science education in the era of a pandemic. Science \& Education, 29, 233-235.

National Science Teaching Association (NSTA) (2020). STEM education teaching and learning. NSTA Position Statement. https://www.nsta.org/about/positions/stem.aspx ().

Office of the Chief Scientist. (2014). Science, technology, engineering and mathematics: Australia's future. Canberra, ACT: Australian Government.

Peters-Burton, E. (2014). Is there a "Nature of STEM"? School Science and Mathematics, 114(3), 99-101.

Publisher's Note Springer Nature remains neutral with regard to jurisdictional claims in published maps and institutional affiliations. 